\title{
Glutathione concentration, glutathione peroxidase and glutathione reductase activity in elderly patients with type II diabetes compared to hypertensives
}

\author{
(INDEX: 23-27/2010 Copernican Letters ${ }^{\circledR}$ Vol 1)
}

\author{
Rybka Joanna, Kupczyk Daria, Kędziora-Kornatowska Kornelia, Kędziora Józef \\ Katedra i Zakład Biochemii, Uniwersytet Mikołaja Kopernika w Toruniu, Collegium \\ Medicum im. L. Rydygiera w Bydgoszczy, tel: (48) 525853755 \\ e-mail: joanna.rybka1@wp.pl
}

\begin{abstract}
Summary
Age-related oxidative stress is generated by a combination of increased production of free radicals, decreased antioxidants levels, diminished activity of antioxidant enzymes and impaired repair of oxidative damages. Oxidative stress is associated with many diseases commonly present in elderly such as hypertension and diabetes. In our study we have observed significantly $(p<0,01)$ increased level of reduced glutathione in treated hypertensive compared to treated diabetic patients $(3,1 \pm$ $0,29 \mathrm{mmol} / \mathrm{L}$ and $2,72 \pm 0,4 \mathrm{mmol} / \mathrm{L}$, respectively) and significantly $(p<0,01)$ increased activity of glutathione reductase $(83,43 \pm 15,25 \mathrm{U} / \mathrm{g} \mathrm{Hb}$ and $65,74 \pm 14,27 \mathrm{U} / \mathrm{g}$ $\mathrm{Hb}$, respectively).
\end{abstract}

\section{Introduction}

The oxidative hypothesis of senescence has been introduced in 1956 by Harman and has become one of the most prolific theories of aging since its origin [1,2]. This agerelated oxidative stress is generated by a combination of increased production of free radicals, decreased antioxidants levels, diminished activity of antioxidant enzymes and impaired repair of oxidative damages. There are many physiological processes in the human body which generate reactive oxygen species (ROS) which due to their unstability and high reactivity are harmful for the cells. To protect themselves from ROS, cells are equipped with antioxidant enzymes i.e. superoxide dismutase (SOD) catalyzes dismutation of $\mathrm{O}_{2}{ }^{-*}$, catalase (CAT) scavenges $\mathrm{H}_{2} \mathrm{O}_{2}$, glutathione peroxidase (GPx) converts $\mathrm{H}_{2} \mathrm{O}_{2}$ to water and neutralizes lipid peroxyl radials. Glutathione serves as a major thioldisulfide redox buffer of the cell and its reduced form pool is maintained by glutathione reductase (GR). When oxidants are produced in excess and overwhelm the cellular antioxidant capacity the state of oxidative stress occurs. This can result in molecular and cellular tissue damage as well as in severe metabolic malfunctions caused by oxygen radical-mediated toxicity [3]. It has been established taht $\mathrm{O}_{2}{ }^{\bullet-}, \mathrm{H}_{2} \mathrm{O}_{2}$ and $\mathrm{ONOO}^{-}$which is formed in radicalradical coupling reactions, play an important role in the development of hypertension due to their effect on vascular tone [4] and the major source of vascular ROS production are NADP $(\mathrm{H})$ oxidases, [5]. Furthermore decreased endogenous antioxidant status has been observed in essential hypertension [6]. Likewise, imbalance between oxidants and antioxidants has been reported in diabetes mellitus [7] and reactive oxygen metabolites increase the autooxidation of glucose and glycosylated proteins as well as activate polyol pathways [8]. Altogether previous results of oxidative stress parameters and antioxidant enzymes activity are divergent and so far we are not able to state explicitly how they change in particular health condition, therefore further studies are required. The aim of this study was to compare concentration of reduced glutathione and activity of glutathione reductase and glutathione peroxidase in diabetes mellitus type II and hypertensive elderly patients. 


\section{Materials and methods}

30 elderly patients age above 60 were recruited to the Department of Gerontology and Clinic of Geriatrics, Nicolaus Copernicus University Collegium Medicum in Bydgoszcz, Poland. There were 12 and 18 patients with type II diabetes and essential hypertension, respectively. Exclusion criteria for both experimental groups were cardiovascular diseases, cancer, dementia, Alzheimer disease, antioxidants supplementation, smoking and alcohol abuse. We distinguished HT group for hypertensive patients currently treated for and DM with no hypertension neither presently nor in medical record. Hypertensive as well as diabetic patients were treated for their condition. Groups were age and sex matched.

The study was approved by the Nicolaus Copernicus University in Torun Human Ethics Committee. Written informed consent was obtained before inclusion in the study.

Venous EDTA anti-coagulated blood samples were taken from the cubital vein. GSH concentration was determined in whole blood (method described by Beutler, 1971), GPx1 and GR activities were determined in erythrocytes from hemolysed blood samples acording to Paglia \& Valentine, 1967; Flohe \& Gunzler methods, respectively. We performed statistical analyses with Statistica version 9 software for the comparisons between measured parameters in experimental groups. Pvalues of less than 0.05 were considered to indicate statistical significance in differences between means of measured parameters.

\section{Results}

The antioxidant barrier defined as antioxidant enzymes activity and concentration of antioxidants in treated elderly patients with diabetes mellitus type two has been demonstrated to function unlike in hypertensive patients. First, in order to analyse whether oxidative stress parameters varied between groups we have measured GSH concentration. The mean GSH concentration (mmol/L) was significantly lower in DM group compared to HT group $(p<0,01)$ with values of $2,7 \pm$ $0,38 \mathrm{mmol} / \mathrm{L}$ and $3,1 \pm 0,29 \mathrm{mmol} / \mathrm{L}$, respectively (Fig.1). Lower concentration of GSH in DM group when compared to HT group, was accompanied by decreased activity of GR (Fig. 2). Mean enzyme activity was significantly lower in diabetics $(p<0,01)$ than in hypertensives. GR exhibited activities of $63,8 \pm 15,15 \mathrm{U} / \mathrm{g} \mathrm{Hb}$ and $83,4 \pm 15,25 \mathrm{U} / \mathrm{g} \mathrm{Hb}$ in $\mathrm{DM}$ and HT groups, respectively. We have also measured GPx activity, however no significant differences between analysed groups were discovered in this case. Activity of GPx1 was as high as 12,76 $\pm 2,65$ $\mathrm{U} / \mathrm{g} \mathrm{Hb}$ and 13,16 $\pm 1,95 \mathrm{U} / \mathrm{g} \mathrm{Hb}$ in patients treated for diabetes and for hypertension, respectively which again follows the pattern of decreased antioxidants in diabetes mellitus type II patients in comparison to hypertensive patients in our study.

Altogether this results suggest that diabetes mellitus type II and essential hypertension which both has been proven to be associated with oxidative stress may differ regarding to mechanisms implicating oxidative stress in their pathogenesis as well as response to medical treatment. 


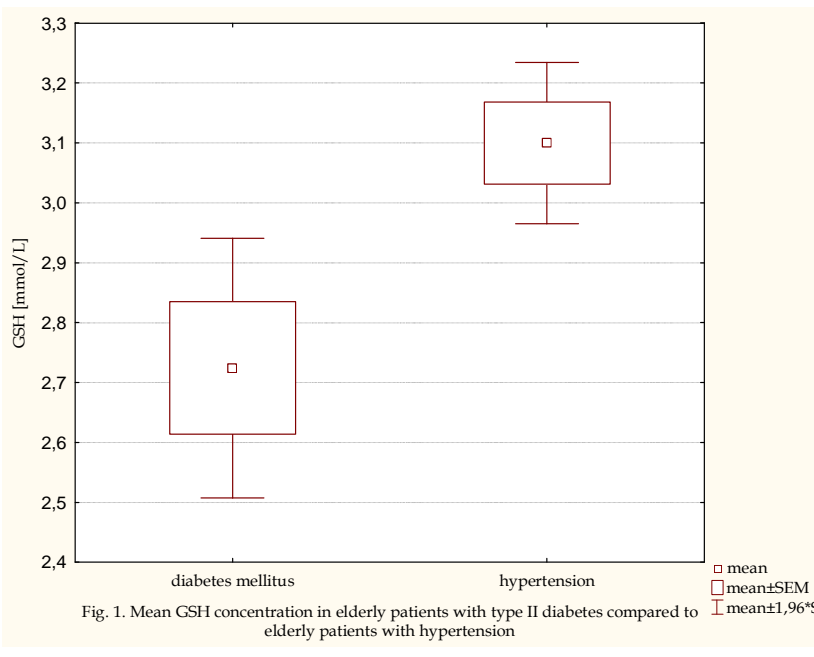

from our groups with healthy controls at the same age. However we have done similar study before and interestingly when parallelly analyzed the same parameters in controls we observed that patients with treated hypertension had significantly higher GSH concentration than subjects from two other groups which have had similar level of GSH. The explanation of this phenomenon may be that antioxidant thiols concentration increase due to higher concentration of ROS which means that hypertensives are more volnurable to oxidative stress. Glutathione deficiency contributes to oxidative stress, which plays important role in aging and the pathogenesis of many diseases such as

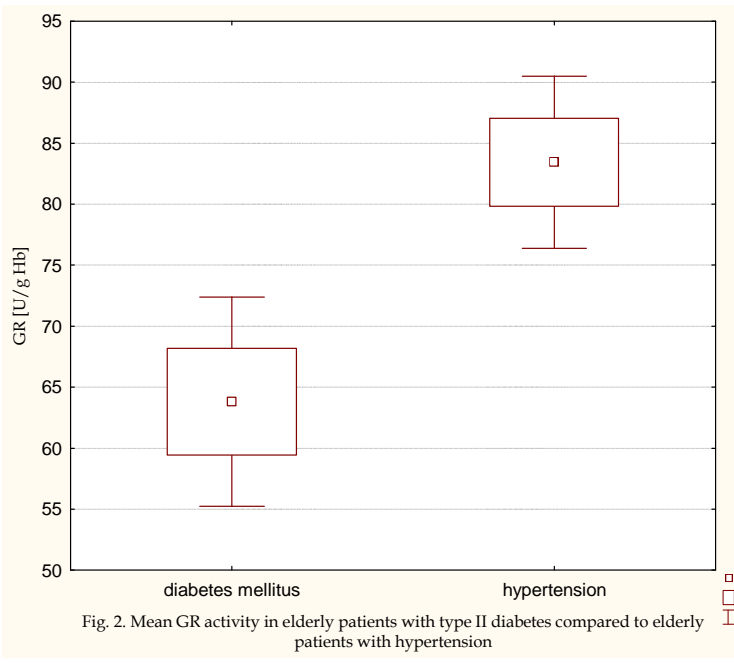

\section{Discussion}

Results from this research suggest significantly decreased level of glutathione (GSH) in treated diabetes type II elderly subjects when compared with these treated for hypertension. Majority of studies reveal decrease of GSH in pathological conditions analysed $[9,10]$ but we can not conclude it from the data presented herein still we have not compared the result of patients diabetes and cardiovascular diseases [11, 12]. On the other hand higher level of reduced glutathione can be considered as better protection against oxidative stress since protective role of glutathione against oxidative stress among other important functions has been recognized [13].

In order to better understand the mechanisms of GSH increase in hypertension the values of other parameters of oxidative stress and antioxidant defense need to be taken into account as well as the fact that important confounder in our study

Was the medication. Antihypertensive drugs are indeed proven to have antioxidant properties [14, 15, 16, 17, 18]. Since hypertensive patients received different antihypertensive drugs with various combinations in this group we could look for the complete status of antihypertensive drugs effect over oxidative stress alone.

The relation between oxidative stress and blood pressure is explained through inactivation of the vasodilator nitric oxide (NO) by ROS and formation of peroxynitrite $\mathrm{ONOO}^{-}$[15]. GSH plays important role in maintenance of NO pool. GSH reacts with peroxynitrite to produce Snitrosoglutathione (GSNO) which extends the half-life of $\mathrm{NO}$ and in consequence contributes in relaxation of vascular tissue 
[20]. GSH enhances decomposition of nitrosothiols and release of NO [21]. Moreover nitrosothiols have the ability to inhibit NADPH oxidase and therefore have beneficial effect on vascular tension. Other important role of GSH is control of PDGFmediated ROS production by $\mathrm{NADH} / \mathrm{NADPH}$ oxidase which is considered to be the main source of vascular $\operatorname{ROS}[5,15,22]$.

Well-established role of GSH is reduction of hydrogen peroxide in the presence of GPx Reduced form of glutathione is restored by glutathione reductase (GR) [13]. In our study GPx1 activity has not differed significantly while comparing two examined groups. Results of other studies concerning GPx activity in HT subjects are contradictory showing both increased and decreased activity of the enzyme [23]. The same conclusion can be made regarding review of diabetes mellitus studies [24, 25]. Although GPx1 remained unchanged, GR activity increased significantly in HT group. This observation has been interrelated with GSH concentration analyses. We assumed that elevated level of glutathione is the result of increased activity of GR. However, this parameters are not significantly correlated in our study.

Protective role of GPx1 in coping with oxidative injury and cell death mediated by reactive oxygen species in vivo has been supported by substantial body of evidence. Among other important functions in coping with oxidative stress GPx possesses the ability to decompose GSNO and is also responsible for lipid hydroperoxides reduction, thereby preventing inactivation of NO [26].

Nevertheless the ability to potentiate reactive nitrogen species stress has been also reported. GPx seems to play contradictory roles in coping with ROS vs. RNS [27].

Altogether our results suggest that the mechanisms which link oxidative stress with various pathological conditions may differ and may be associated with changes of different parameters depending of the pathogenesis of the condition and furthermore the action of pharmaceutical agents.

\section{REFERENCES}

[1] D. Harman, "Aging: A theory based on free radical and radiation chemistry." J Gerontol 1956; 11: s. 298-300.

[2] D. Harman, "Free radical theory of aging: An update: Increasing the functional life span." Ann N Y Acad Sci 2006; 1067: s. 1021.

[3] M. Valko, "Free radicals and antioxidants in normal physiological functions and human disease." Int J Biochem Cell Bi 2007; 39: s. 44-84.

[4] A. Ceriello, "Possible role of oxidative stress in the pathogenesis of hypertension." Diabetes Care 2008 ; 31(Suppl 2): s. 181-184.

[5] G. Csányi, R.W. Taylor, P.J. Pagano, “Nox and inflammation in the vascular adventitia." Free Radic Biol Med 2009; 47: s. 1254-1266.

[6] J. Pedro-Botet, M. Covas, S. Martin and J. Rubies-Prat, "Decreased endogenous antioxidant enzymatic status in essential hypertension." J Hum Hypertens 2000; 14(6): s. 343-345.

[7] K. Kędziora-Kornatowska, H. Pawluk, T. Kornatowski, L. Szadujkis-Szadurski, J. Czuczejko, K. Szewczyk-Golec, J. Motyl, J. Kędziora, „Peroksydacja lipidów a glutationozależna obrona antyoksydacyjna $\mathrm{u}$ chorych $\mathrm{z}$ cukrzycą typu 2 w wieku podeszłym." Geriatr Pol 2006; 3: s. 183-189.

[8] I.B. Afanas'ev, "Free radical mechanism of aging processes under physiological conditions." Biogerontology 2005; 6(4): s. 283-290.

[9] G. Donmez, U. Derici, D. Erbas, T. Arinsoy, A. Onk, S. Sindel and E. Hasanoglu, "The effects of losartan and enalapril therapies on levels of nitric oxide, malondialdehde, and glutathione in patients with essential hypertension." Jpn J Physol 2002; 2: s. 435440.

[10] K. Kędziora-Kornatowska, K. Szewczyk-Golec, J. Czuczejko, H. Pawluk, K. van Marke de Lumen, M. Kozakiewicz, G. Bartosz, J. Kędziora, “Antioxidative effects of melatonin administration in elderly 
primary essential hypertension patients." J Pineal Res 2008; 45(3): s. 312 - 317.

[11] G. Bartosz, "Druga twarz tlenu." PWN, Warszawa, 2003, pp. 13-14

[12] R. Franco, O.J. Schoneveld, A. Pappa, M.I. Panayiotidis, “The central role of glutathione in the pathophysiology of human diseases." Arch Physiol Biochem 2007; 113(4-5): s. 234-258.

[13] G. Wu, Y.Z. Fang, S. Yang, J.R. Lupton, N.D. Turner, "Glutathione metabolism and its implications for health." J Nutr 2004; 134: s. 489-492.

[14] L. Ghiadoni, A. Magagna, D. Versari, I. Kardasz, Y. Huang, S. Taddei, A. Salvetti, "Different Effect of Antihypertensive Drugs on Conduit Artery Endothelial Function." Hypertension 2003; 41: s. 1281-1286.

[15] E. Grossman, "Does increased oxidative stress cause hypertension." Diabetes Care 2008; 31( Suppl. 2): s. 185-189.

[16] N.C. Ward, J.M. Hodgson, I.B. Puddey, T.A. Mori, L.J. Beilin, K.D. Croft, "Oxidative stress in human hypertension: association with antihypertensive treatment, gender, nutrition, and lifestyle." Free Radic Biol Med 2004; 36(2): s. 226-232.

[17] S. Wassmann, K. Wassmann, G. Nickenig, "Modulation of oxidant and antioxidant enzymes expression and function in vascular cells." Hypertension 2004; 44: s. 381-386.

[18] R. Rodrigo, H. Prat, W. Passalacqua, J. Araya, C. Guichard, J.P. Bächler, "Relationship between oxidative stress and essential hypertension." Hypertens Res 2007; 30(12): s. 1159-1167.

[19] G. Wu, Y.Z. Fang, S. Yang, J.R. Lupton, N.D. Turner, "Glutathione metabolism and its implications for health." J Nutr 2004; 134: s. 489-492

[20] R.M. Uppu, B.D. Nossaman, A.J. Greco, A. Fokin, S.N. Murthy, V.A. Fonseca, P.J. Kadowitz, "Cardiovascular effect of peroxynitrite." Clin Exp Pharmacol Physiol 2007; 34: s. 933-937.

[21] D.R. Noble, H.R. Swift and D.L.H. Williams, "Nitric oxide release from Snitrosoglutathione (GSNO)." Chem Commun 1999; 22: s. 2317-2318.

[22] M. Sedeek, R.L. Hebert, C.R. Kennedy, K.D. Burns, R.M. Touyz, "Molecular mechanisms of hypertension: role of Nox family NADPH oxidases." Curr Opin Nephrol Hypertens 2009; 18(2): s. 122127.
[23] J. Redón, M.R. Oliva, C. Tormos, V. Giner, J. Chaves, "Antioxidant activities and oxidative stress byproducts in human hypertension." Hypertension 2003; 41(5): s. 1096-1101.

[24] E. Szaleczky, J. Prechl, J. Fehér, A. Somogyi, "Alterations in enzymatic antioxidant defence in diabetes mellitus-a rational approach." Postgrad Med J 1999; 75: s. 13-17.

[25] E.B. Bolajoko, K.S. Mossanda, F. Adeniyi, O. Akinosun, A. Fasanmade, M. Moropane, "Antioxidant and oxidative stress status in type 2 diabetes and diabetic foot ulcer." S Afr Med J 2008; 98(8): s. 614617.

[26] J.E. Freedman, F. Balz, G.N. Welch, J. Loscalzo, "Glutathione peroxidase potentiates the inhibition of platelet function by S-Nitrosothiols." J Clin Invest 1995; 96: s. 394-400.

[27] X.G. Lei, W.H. Cheng and J.P. McClung, "Metabolic regulation and function of glutathione peroxidase-1." Annu Rev Nutr 2007; 27: s. 41-61. 